\title{
Reliability of Two Methods of Evaluation of the Apical Limit of Obturation of Root Canals of Primary Teeth: A Pilot Study
}

\author{
Maysa Lannes Duarte ${ }^{1}$, Julia Cocchiarale Pepino ${ }^{\circledR}$, Mariana Coutinho Sancas²@, Jéssica \\ Pronestino de Lima Moreira ${ }^{3}$, Aline de Almeida Neves ${ }^{4,5}{ }^{\circledR}$, Andréa Vaz Braga Pintor ${ }^{1}\left(\mathbb{C}_{\text {, Laura }}\right.$ \\ Guimarães Primo ${ }^{4}$ (1)
}

\begin{abstract}
${ }^{1}$ Post-Graduate Program in Pediatric Dentistry, Faculty of Dentistry, Federal University of Rio de Janeiro, Rio de Janeiro, RJ, Brazil.

${ }^{2}$ Faculty of Dentistry, Federal University of Rio de Janeiro, Rio de Janeiro, RJ, Brazil.

${ }^{3}$ Post-Graduate Program in Biomedical Engineering, Federal University of Rio de Janeiro, Rio de Janeiro, RJ, Brazil.

${ }^{4}$ Department of Pediatric Dentistry and Orthodontics, Faculty of Dentistry, Federal University of Rio de Janeiro, Rio de Janeiro, RJ, Brazil

${ }^{5}$ Faculty of Dentistry, Oral \& Craniofacial Sciences, King's College London, London, United Kingdom.
\end{abstract}

Author to whom correspondence should be addressed: Professor Laura Guimarães Primo, Disciplina de Odontopediatria da FO-UFRJ, Av. Prof. Rodolpho Paulo Rocco, 325, Cidade Universitária, CCS, Rio de Janeiro, RJ, Brazil. 21941-913. Phone: +55213938-2098. E-mail: 1primo@pobox.com.

Academic Editors: Alessandro Leite Cavalcanti and Wilton Wilney Nascimento Padilha

Received: 08 August 2019 / Accepted: 13 March 2020 / Published: 01 April 2020

How to cite this article: Duarte ML, Pepino JC, Sancas MC, Moreira JPL, Neves AA, Pintor AVB, et al. Reliability of two methods of evaluation of the apical limit of obturation of root canals of primary teeth: a pilot study. Pesqui Bras Odontopediatria Clín Integr. 2020; 20:e5 108. https://doi.org/10.1590/pboci.2020.058

\begin{abstract}
Objective: To verify the concordance in the evaluation of the apical limit of obturation (ALO) in filled root canals of primary teeth between digital and visual methods. Material and Methods: Twenty periapical radiographs of endodontically treated primary teeth were digitalized and evaluated by an endodontics specialist (E1), a PhD pediatric dentist (E2), and a MSc general dentist (E3). Calibrated evaluators (Kappa = 1.00) analysed the images in a light-isolated environment two times (D1 and D2) with a one-week interval between evaluations. ALO scores were categorized as overfilled, flush-filled and underfilled. Results: The intra-rater reliability between methods was 0.82 (D1) and 0.75 (D2) for E1, 0.93 (D1 and D2) for E2, and 0.94 (D1 and D2) for E3. Inter-rater reliability ranged from $0.71(\mathrm{E} 1 \times \mathrm{E} 3)$ and $1.00(\mathrm{E} 1 \times \mathrm{E} 2)$ for the visual method to $0.76(\mathrm{E} 1 \times \mathrm{E} 3)$ and $0.88(\mathrm{E} 1 \times \mathrm{E} 2)$ for the digital method. Spearman correlation coefficients showed a similar ranking among the evaluators. There was greater disagreement among the underfilled and ideal scores. For all evaluators, the digital method favoured the identification of the ideal score. Conclusion: Both methods are suitable for the determination of the ALO of filled primary teeth and can be used in clinical practice.
\end{abstract}

Keywords: Dimensional Measurement Accuracy; Radiography, Dental; Root Canal Obturation. 


\section{Introduction}

Pulpectomy is indicated for primary teeth with irreversible pulpitis or pulp necrosis. This procedure includes the removal of inflamed or necrotic pulp tissue by debridement, widening and disinfection of the root canals and subsequent filling with resorbable filling paste [1]. The goal of this treatment is to maintain the primary tooth in the oral cavity, without symptoms until exfoliation, thus preserving arch length, correct tongue positioning, normal masticatory function, aesthetics and speech without alterations [2,3].

The success of endodontic treatment is clinically characterized by the absence of signs or symptoms of infection, including pain, edema, fistula or percussive sensitivity during the preservation of the tooth $[2,4,5]$. This is also related to precise determination of the root canal length and, consequently, to the apical limit of obturation (ALO). After endodontic treatment, it is radiographically expected that the filling of the root canal system should be dense and three-dimensional, approximating the cementodentinal junction and not exceeding the limit of the radiographic apex [6]. Systematic reviews have shown that chemomechanical preparation and filling of the root canal at 1 to $2 \mathrm{~mm}$ below the radiographic apex were associated with a better prognosis and that overfilling slows down the apical repair process, respectively [7].

In the literature, there are at most two studies [8,9] about ALO digital evaluations of permanent teeth through software for image analysis. Moreover, no studies were found on primary teeth. Thus, it is relevant to perform a study whose objective is to compare two methods of evaluating the ALO in primary teeth (digital and visual) and to correlate the ALO evaluated with the type of root canal filling used.

\section{Material and Methods}

Study Design and Sample

In this pilot study, we evaluated an image database consisted of 27 final radiographs from a previous study [5]. From these, 20 were selected according to the inclusion criteria: periapical radiographs of anterior deciduous teeth with good quality. The others were excluded since they were posterior teeth radiographs. This image database was selected since a single operator used the same technique and performed the radiographs, being considered standard.

\section{Data Collection}

A single operator, specialist and master in Pediatric Dentistry, performed the radiographs immediately after pulpectomy, using the parallelism technique with radiographic positioners (Indusbello, Londrina, PR, Brazil) and the time and temperature processing method. In all patients, the root canal had been filled with iodoform paste $(\mathrm{n}=10)$ or calcium hydroxide paste thickened with zinc oxide $\left(\mathrm{Calen}^{\circledR} / \mathrm{ZO}\right.$; SS White Artigos Dentários Ltda., Rio de Janeiro, RJ, Brazil) ( $\mathrm{n}=10)$ [5]. Radiograph scans (Scanner HP Scanjet G4050, Development Company, Silicon Valley, California, USA) were standardized with a resolution at 300 dpi and 256-grey level. The images were stored on a computer in a JPEG-compressed file format.

Prior to ALO evaluation, three evaluators were calibrated (Kappa = 1.00) for the two methods (visual and digital) by means of the analysis of five nonsample periapical radiographs of anterior primary teeth with root canals filled with different root canal filling materials. The evaluators were an endodontics specialist (E1), a $\mathrm{PhD}$ pediatric dentist (E2) and a MSc general dentist (E3). Analyses were performed in the same environment and with the same conditions (i.e., environment devoid of light) for both tests. To aid in the use of the ImageJ image processing software (NIH, Bethesda, MD, USA), a tutorial was designed by the researchers 
to evaluate the ALO through the resources offered by the program. Each evaluator received a hard copy for consultation during evaluation using the digital method.

The methods used to determine the ALO were as follows:

- Visual Method: Radiographs were analysed using an X-ray viewer (Gold line ${ }^{\circledR}$, VHSOFTLINE, Araraquara, São Paulo, Brazil) and a hand magnifying glass with a magnification of $3 \times$ as well as a black cardboard mask with a window compatible with the size of the radiographic film.

- Digital Method: Radiographs were analysed using an ASUS ${ }^{\circledR}$ X451C (ASUS do Brasil, Cotia, São Paulo, Brazil) Windows 8 computer with a 14' monitor, using the ImageJ free image-editing software. The size of the radiograph was measured through a horizontal line between the borders aiming to calibrate the image $(\mathrm{mm})$ in reference to the real size of the radiographic film, using the 'set scale' tool. The images were magnified to $75 \%$. ALO measurement was made through a straight line drawn using the 'straight' tool, from the end of the canal obturation to the tooth radiographic apex, followed by the use of the 'analyse' and 'measure' tools. Subsequently, the program calculated a measure in millimeters of the line ('results').

To compare the visual and digital methods, the scores of the select study to digital evaluation [8] were stratified into three scores: 0 - overfilled; scores 1 and 2 - ideal; scores 3 and 4 - underfilled, following the classification used to visual method [4]. Thus, we used an adaptation of the table of a previous study [8]. ALO scores for both methods are described in Table 1.

Table 1. Distance scores between the filling material and the tooth radiographic apex for both methods.

\begin{tabular}{ccll}
\hline \multicolumn{1}{c}{ Author } & Method & \multicolumn{1}{c}{ Score } & \multicolumn{1}{c}{ Description } \\
\hline Barcelos et al. [4] & Visual & Underfilled & Sealer at $1 \mathrm{~mm}$ or more short of radiographic apex. \\
& & Ideal & Sealer paste at radiographic apex level. \\
& & Overfilled & Sealer paste extruded beyond radiographic apex. \\
Adaptation of Dovigo et al. [8] & Digital & Underfilled & Limit of 1.1 mm or more below the radiographic apex. \\
& & Ideal & Limit from 0.0 to 1.0 mm below the radiographic apex. \\
& & Overfilled & Extruded filling material in the periapice. \\
\hline
\end{tabular}

All radiographs were evaluated twice by the two methods separately and by three examiners, with a one-week time interval. The evaluators were blinded to the type of root canal filling material used.

A researcher not involved in the image evaluation process (MCS) was in charge of the randomization process. Using the software Excel (Microsoft Corporation, Albuquerque, USA), we randomly assigned a number to each of the 20 radiographs selected, determining the sequence in which they would be analysed by the assigned evaluator at each time (D1 and D2). The radiographs were placed in numbered opaque envelopes, according to the generated sequence, and distributed to the researchers on each evaluation day. Thus, in each assessment, the radiographs were evaluated in random and different sequences. The scanned images were organized in the determined order, in different digital folders, referring to each evaluation day.

\section{Data Analysis}

The data were tabulated in a database in the Statistical Package for the Social Science (SPSS) for Windows Software, version 21.0 (IBM Corp., Armonk, NY, USA) and subjected to descriptive and comparative analysis, including absolute distributions, percentages, and analyses of agreement through the weighted Kappa index and Spearman's correlation test to verify the results. 
Ethical Aspects

This research was previously submitted and approved by the Research Ethics Committee of Federal University of Rio de Janeiro (CAAE 36760614.0.2001.5257).

\section{Results}

Table 2 describes the results of the ALO evaluation and intra-rater reliability of the three evaluators according to the two methods at the two evaluation times. Regarding the intra-rater reliability between methods, E1 disagreed with the identification of the ALO in three cases (Kappa $=0.82$ for D 1 and 0.75 for D2). In the digital method, case nine was classified on the first day (D1) as overfilled and on the second day (D2) as underfilled. Case 10 in the visual method at D1 was classified as underfilled and, at D2, overfilled. Case 12 in the digital method was classified at D1 as ideal and at D2 as underfilled.

E2 and E3 similarly identified all cases in the digital and visual evaluations individually (Kappa = 1.00). When comparing the results of the evaluations between the visual and digital methods, E2 disagreed only in case 14 (Kappa $=0.93)$. E2 classified it as underfilled in the visual method and as ideal in the digital method. The same situation occurred with E3, but in case 10, in which the visual method was classified as underfilled and by the digital was classified as ideal (Kappa $=0.94)($ Table 2).

Table 2. Results of ALO evaluations of the three evaluators and intra-rater reliability (Kappa) of the two methods at two times.

\begin{tabular}{|c|c|c|c|c|c|c|c|c|c|c|c|c|}
\hline \multirow{3}{*}{ Evaluator } & \multirow{3}{*}{ Score } & \multicolumn{4}{|c|}{ Visual } & \multicolumn{5}{|c|}{ Digital } & \multirow{3}{*}{ Карра } & \multirow{3}{*}{$\begin{array}{c}\text { Kappa } \\
\text { between } \\
\text { Methods }\end{array}$} \\
\hline & & \multicolumn{2}{|c|}{ Day 1} & \multicolumn{2}{|c|}{ Day 2} & \multirow[t]{2}{*}{ Kappa } & \multicolumn{2}{|c|}{ Day 1} & \multicolumn{2}{|c|}{ Day 2} & & \\
\hline & & $\mathrm{N}$ & $\%$ & $\mathrm{~N}$ & $\%$ & & $\mathrm{~N}$ & $\%$ & $\mathrm{~N}$ & $\%$ & & \\
\hline \multirow[t]{3}{*}{$\mathrm{E} 1$} & Underfilled & 5 & 25 & 6 & 30 & 0.87 & 5 & 25 & 4 & 20 & 0.81 & $0.82\left(\mathrm{D} 1^{*}\right)$ \\
\hline & Ideal & $\mathrm{O}$ & $\mathrm{O}$ & $\mathrm{O}$ & 0 & & 3 & 15 & 2 & 10 & & $0.75\left(\mathrm{D}^{+}{ }^{\dagger}\right)$ \\
\hline & Overfilled & 15 & 75 & 14 & 70 & & 12 & 60 & 14 & 70 & & \\
\hline \multirow[t]{3}{*}{$\mathrm{E} 2$} & Underfilled & 5 & 25 & 5 & 25 & 1.00 & 5 & 25 & 5 & 25 & 1.00 & 0.93 \\
\hline & Ideal & O & $\mathrm{O}$ & $\mathrm{O}$ & $\mathrm{O}$ & & 1 & 5 & 1 & 5 & & \\
\hline & Overfilled & 15 & 75 & 15 & 75 & & 14 & 70 & 14 & 70 & & \\
\hline \multirow[t]{3}{*}{ E3 } & Underfilled & 5 & 25 & 5 & 25 & 1.00 & 5 & 25 & 5 & 25 & 1.00 & 0.94 \\
\hline & Ideal & 3 & 15 & 3 & 15 & & 4 & 20 & 4 & 20 & & \\
\hline & Overfilled & 12 & 60 & 12 & 60 & & 11 & 55 & 11 & 55 & & \\
\hline
\end{tabular}

*D1: Day One; + D2: Day Two

Weighted Kappa inter-rater values ranged from $0.71(\mathrm{E} 1 \times \mathrm{E} 3)$ and $1.00(\mathrm{E} 1 \times \mathrm{E} 2)$ to $0.76(\mathrm{E} 1 \times \mathrm{E} 3)$ and $0.88(\mathrm{E} 1 \times \mathrm{E} 2)$ for the visual method, as shown in Table 3 . There was greater agreement between E1 and E2 regarding the visual method, since disagreement occurred in just one case. For the digital method, the reliability, when comparing E1 $\times$ E2 and E2 $\times$ E3, was equal, and disagreement occurred in three cases. There was greater disagreement in the underfilled and ideal scores. Two cases were discordant between at least two of the evaluators when comparing the digital and visual methods. For all three evaluators, the digital method favoured the identification of the ideal score. Spearman correlation coefficients showed a similar ranking among the evaluators (Table 4).

Table 3. Inter-rater reliability (Kappa) of the two methods at the two times.

\begin{tabular}{lcccc}
\hline Evaluators & \multicolumn{2}{c}{ Visual } & \multicolumn{2}{c}{ Digital } \\
& Day 1 & Day 2 & Day 1 & Day 2 \\
\hline E1 x E2 & 1.00 & 0.87 & 0.88 & 0.80 \\
E1 x E3 & 0.82 & 0.71 & 0.87 & 0.76 \\
E2 x E3 & 0.82 & 0.82 & 0.82 & 0.82 \\
\hline
\end{tabular}


Table 4. Coefficient correlations (Spearman) between the three evaluators (E1, E2 and E3).

\begin{tabular}{|c|c|c|c|c|c|c|c|c|c|c|c|c|}
\hline & \multicolumn{4}{|c|}{ E1 } & \multicolumn{4}{|c|}{ E2 } & \multicolumn{4}{|c|}{ E3 } \\
\hline & \multicolumn{2}{|c|}{ Visual } & \multicolumn{2}{|c|}{ Digital } & \multicolumn{2}{|c|}{ Visual } & \multicolumn{2}{|c|}{ Digital } & \multicolumn{2}{|c|}{ Visual } & \multicolumn{2}{|c|}{ Digital } \\
\hline & $\mathrm{D}_{1+}+$ & $\mathrm{D} 2_{+}^{+}$ & $\mathrm{D}_{1}+$ & $\mathrm{D} 2+$ & $\mathrm{D}_{1+}+$ & $\mathrm{D} 2+$ & $\mathrm{D}_{1}+$ & $\mathrm{D} 2+$ & $\mathrm{D}_{1}+$ & $\mathrm{D} 2+$ & $\mathrm{D}_{1}+$ & $\mathrm{D} 2+$ \\
\hline Visual D1 ${ }^{\dagger}$ & 1.00 & $0.88^{*}$ & $0.86^{*}$ & $0.72^{*}$ & $1.00^{*}$ & $1.00^{*}$ & $0.94^{*}$ & $0.94^{*}$ & $0.86^{*}$ & $0.86^{*}$ & $0.83^{*}$ & $0.83^{*}$ \\
\hline Visual D $\mathcal{Q}_{+}^{+}$ & $0.88^{*}$ & 1.00 & $0.89^{*}$ & $0.80^{*}$ & $0.88^{*}$ & $0.88^{*}$ & $0.81^{*}$ & $0.81^{*}$ & $0.72^{*}$ & $0.72^{*}$ & $0.85^{*}$ & $0.85^{*}$ \\
\hline Digital D $1 \uparrow$ & $0.86^{*}$ & $0.89^{*}$ & 1.00 & $0.82^{*}$ & $0.86^{*}$ & $0.86^{*}$ & $0.90^{*}$ & $0.90^{*}$ & $0.78^{*}$ & $0.78^{*}$ & $0.84^{*}$ & $0.84^{*}$ \\
\hline Digital D $2_{+}^{+}$ & $0.72^{*}$ & $0.80^{*}$ & $0.82^{*}$ & 1.00 & $0.72^{*}$ & $0.72^{*}$ & $0.80^{*}$ & $0.80^{*}$ & $0.69^{*}$ & $0.69^{*}$ & $0.78^{*}$ & $0.78^{*}$ \\
\hline Visual D ${ }^{\dagger}$ & $1.00^{*}$ & $0.88^{*}$ & $0.86^{*}$ & $0.72^{*}$ & 1.00 & $1.00^{*}$ & $0.94^{*}$ & $0.94^{*}$ & $0.86^{*}$ & $0.86^{*}$ & $0.83^{*}$ & $0.83^{*}$ \\
\hline Visual D2 + & $1.00^{*}$ & $0.88^{*}$ & $0.86^{*}$ & $0.72^{*}$ & $1.00^{*}$ & 1.00 & $0.94^{*}$ & $0.94^{*}$ & $0.86^{*}$ & $0.86^{*}$ & $0.83^{*}$ & $0.83^{*}$ \\
\hline Digital D $1 \uparrow$ & $0.94^{*}$ & $0.81^{*}$ & $0.90^{*}$ & $0.80^{*}$ & $0.94^{*}$ & $0.94^{*}$ & 1.00 & $1.00^{*}$ & $0.90^{*}$ & $0.90^{*}$ & $0.87^{*}$ & $0.87^{*}$ \\
\hline Digital D $\mathcal{2}_{+}^{+}$ & $0.94^{*}$ & $0.81^{*}$ & $0.90^{*}$ & $0.80^{*}$ & $0.94^{*}$ & $0.94^{*}$ & $1.00^{*}$ & 1.00 & $0.90^{*}$ & $0.90^{*}$ & $0.87^{*}$ & $0.87^{*}$ \\
\hline Visual D ${ }^{\dagger}$ & $0.86^{*}$ & $0.72^{*}$ & $0.78^{*}$ & $0.69^{*}$ & $0.86^{*}$ & $0.84^{*}$ & $0.90^{*}$ & $0.90^{*}$ & 1.00 & $1.00^{*}$ & $0.95^{*}$ & $0.95^{*}$ \\
\hline Visual $\mathrm{D} \mathcal{Q}_{+}^{+}$ & $0.86^{*}$ & $0.72^{*}$ & $0.78^{*}$ & $0.69^{*}$ & $0.86^{*}$ & $0.84^{*}$ & $0.90^{*}$ & $0.90^{*}$ & $1.00^{*}$ & 1.00 & $0.95^{*}$ & $0.95^{*}$ \\
\hline Digital D $1{ }^{\dagger}$ & $0.83^{*}$ & $0.85^{*}$ & $0.84^{*}$ & $0.78^{*}$ & $0.83^{*}$ & $0.83^{*}$ & $0.87^{*}$ & $0.87^{*}$ & $0.95^{*}$ & $0.95^{*}$ & 1.00 & $1.00^{*}$ \\
\hline Digital D $2_{+}^{+}$ & $0.83^{*}$ & $0.85^{*}$ & $0.84^{*}$ & $0.78^{*}$ & $0.83^{*}$ & $0.83^{*}$ & $0.87^{*}$ & $0.87^{*}$ & $0.95^{*}$ & $0.95^{*}$ & $1.00^{*}$ & 1.00 \\
\hline
\end{tabular}

*The correlation is significant at the 0.01 level (2 extremities); $\uparrow \mathrm{D} 1$ : Day One; †D2: Day Two.

Considering the root canal filling materials, in the five cases in which there was some disagreement, three were filled with Calen ${ }^{\circledR} / Z$ Z. None of the teeth filled with iodoform paste was classified as overfilled, while three teeth filled with Calen ${ }^{\circledR} / \mathrm{ZO}$ were classified as overfilled in some of the evaluations. Four cases classified as ideal were treated with Calen ${ }^{\circledR} / \mathrm{ZO}$ and three with iodoform paste. In the visual method, three of the four cases in which a disagreement occurred were filled with Calen ${ }^{\circledR} / Z O$. In the digital evaluation, three of the five cases of disagreement belonged to the same group.

\section{Discussion}

Radiographic examination in endodontics is a fundamental part of the final verification of the adequate sealing of the root canals, determination of the ALO, periodical follow-up and inspection of the integrity of the periapical tissues [6]. In addition, the ALO evaluation may be an important predictor of the prognosis of endodontic treatment [7]. Frequently, radiographic analysis for ALO determination is performed through visual methods $[6,8,10]$. It is important to emphasize that, despite their greater use, the limitations of visual interpretation must always be considered, due to subjectivity and training, leading to an impairment of interpretation in terms of precision, prediction or objectivity [11]. Meanwhile, the digital method, through the auxiliary resources such as magnification of the images and tools to measure regions of interest, can assist dentists in the evaluation of the ALO. Moreover, the digital method presents an advantage in terms of the possibility of storing the images evaluated, allowing comparisons over time and by different examiners, regardless of their location.

Association of the quality of root canal obturation and the success of endodontic treatment in permanent teeth has been previously assessed $[6,8,10,12,13]$. The ALO was pointed out as one of the factors interfering in the repair of apical lesions [12]. Furthermore, the quality of root canal obturation demonstrated a correlation with endodontic failure [7,12-14]. In clinical trials with primary teeth, the evaluation of the quality of obturation was performed only by the visual method [4,5,15-17], so, to our knowledge, this is the first study that has evaluated the limit of obturation of primary canals by use of the digital method. Since there are no similar studies in the literature with this methodology, the comparison with a gold standard method became limited.

The failure of pulpectomies in this study was not associated with overfilling [5]. However, due to the different factors that may influence clinical and radiographic success, no conclusion could be inferred in 
relation to the ALO evaluated and the frequency of success. Future studies should be carried out to consolidate the results found.

It was possible to observe a slight increase in the agreement between the examiners in the visual method as compared with the digital method for the evaluation of the ALO. This can be attributed to the fact that the visual method is more widespread and performed among professionals in all levels of education. However, the agreement index in the digital method was also considered excellent for all three evaluators. Thus, the agreement between the evaluators was considered high in both methods, although they have different degrees of training levels, this was not reflected in the agreement rates, as seen in the results. This can be explained by the fact that the digital method was a new technique for all training levels of evaluators. Whenever evaluators are exposed to new assessment models, they must receive rigorously training and calibration, as occurred in the present experiment [18].

The scores that generated the most doubts among the evaluators were underfilled and ideal, due to the difficulty in determining the root apex in relation to the end of obturation here. As described previously for another authors [19], in primary teeth, the anatomical variation of the location of the apical foramen as well as the superposition of structures and the presence of periapical lesions may hinder the correct determination of the ALO. When the material overflows apically, characterizing overfilling, the overflow of the material in the tissues facilitates determination of the condition. This can explain the difficulty in evaluating primary molar fillings due to the overlapping of root images, which is a limitation of the experiment.

Regarding the root canal filling materials used in the study, a higher agreement was observed between the teeth that were filled with the iodoform paste for both evaluation methods. This fact can be related to the difference in radiopacity between the materials, which is more intense for iodoform paste when compared with Calen $^{\circledR} / \mathrm{ZO}[20]$.

\section{Conclusion}

Both methods can be used to determine the ALO. A high intra-examiner index agreement was observed. Regarding root canal filling, the two methods demonstrated similar performance. We can also highlight that, with an increase in the use of digital radiographs, the use of image software in new research is a promising proposal

\section{Authors' Contributions}

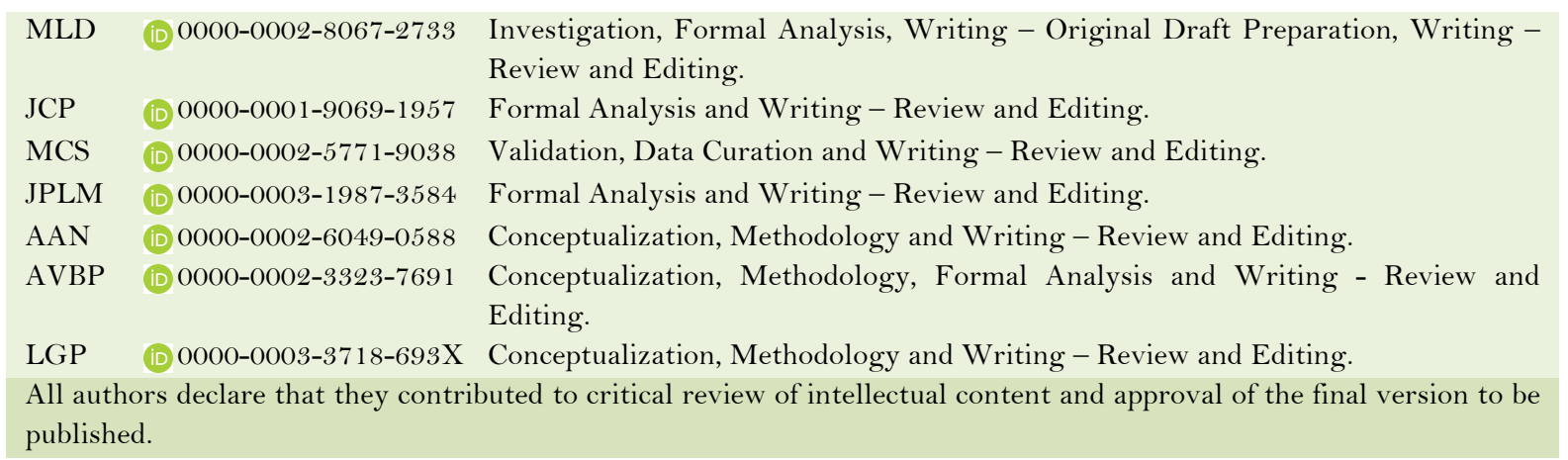

\section{Financial Support}

This study was financed in part by the Coordenação de Aperfeiçoamento de Pessoal de Nível Superior, Brasil (CAPES) (Finance Code 001) and FAPERJ (Grant No. E-26/202-399/2017). 


\section{Conflict of Interest}

The authors declare no conflicts of interest.

\section{References}

[1] American Academy on Pediatric Dentistry. Clinical Affairs Committee. Pulp Therapy Subcommittee. Pulp therapy for primary and immature permanent teeth. Pediatr Dent 2018; 40(6):343-51.

[2] Benenati FW, Khajotia SS. A radiographic recall evaluation of 894 endodontic cases treated in a dental school setting. J Endod 2002; 28(5):391-5. https://doi.org/10.1097/00004770-200205000-00011

[3] Beltrame AP, Triches TC, Sartori N, Bolan M. Electronic determination of root canal working length in primary molar teeth: an in vivo and ex vivo study. Int Endod J 2011; 44(5):402-6. https://doi.org/10.1111/j.1365-2591.2010.01839.x

[4] Barcelos R, Tannure PN, Gleiser R, Luiz RR, Primo LG. The influence of smear layer removal on primary tooth pulpectomy outcome: a 24-month, double-blind, randomized, and controlled clinical trial evaluation. Int J Paediatr Dent 2012; 22(5):369-81. https://doi.org/10.1111/j.1365-263X.2011.01210.x

[5] Cassol DV, Duarte ML, Pintor AVB, Barcelos R, Primo LG. Iodoform vs calcium hydroxide/zinc oxide based pastes: 12-month findings of a randomized controlled trial. Braz Oral Res 2019; 33:e002. https://doi.org/10.1590/1807-3107bor-2019.vol33.0002

[6] Ferreira HLJ, Paula MVQ, Guimarães SMR. Radiographic evaluation of the root canal obturation. Rev Odonto Ciênc 2007; 22(58):340-5.

[7] Holland R, Gomes JE Filho, Cintra LTA, Queiroz ÍOA, Estrela C. Factors affecting the periapical healing process of endodontically treated teeth. J Appl Oral Sci 2017; 25(5):465-76. https://doi.org/10.1590/1678-7757-2016-0464

[8] Dovigo LN, Campos JADB, Pappen FG, Leonardo RT. The apical limit of filling and the clinical and radiographic success of teeth with dental pulp necrosis and periapical lesions. RGO 2006; 54(3):249-53.

[9] Pedro FM, Marques A, Pereira TM, Bandeca MC, Lima S, Kuga MC, et al. A status of endodontic treatment and the correlations to the quality of root canal filling and coronal restoration. J Contemp Dent Pract 2016; 17(10):830-6.

[10] Freitas RG, Cogo DM, Kopper PMP, Santos RB, Grecca FS. Evalution of the quality of the root canal filligs accomplished by undergraduate students. Rev Fac Odontol Porto Alegre 2008; 49(3):24-7.

[11] Travassos RMC, Caldas Junior AF, Albuquerque DS. Cohort study of endodontic therapy success. Braz Dent J 2003; 14(2):109-13. https://doi.org/10.1590/So 103-64402003000200007

[12] Soares JA, Leonardo RT. Influence os Smear Layer on periapical repair of teeth with necrotic pulp and periapical lesions. Rev Bras Odontol 2001; 58(4):240-3.

[13] Kojima K, Inamoto K, Nagamatsu K, Hara A, Nakata K, Morita I, et al. Success rate of endodontic treatment of teeth with vital and nonvital pulps. A meta-analysis. Oral Surg Oral Med Oral Pathol Oral Radiol Endod 2004; 97(1):95-9. https://doi.org/10.1016/j.tripleo.2003.07.006

[14] Estrela C, Holland R, Estrela CR, Alencar AH, Sousa-Neto MD, Pécora JD. Characterization of successful root canal treatment. Braz Dent J 2014; 25(1):3-11. https://doi.org/10.1590/0103-6440201302356

[15] Fuks AB, Eidelman E, Pauker N. Root fillings with Endoflas in primary teeth: a retrospective study. J Clin Pediatr Dent 2002; 27(1):41-5.

[16] Sari S, Okte Z. Success rate of Sealapex in root canal treatment for primary teeth: 3-year follow-up. Oral Surg Oral Med Oral Pathol Oral Radiol Endod 2008; 105(4):e93-6. https://doi.org/10.1016/j.tripleo.2007.12.014

[17] Rewal N, Thakur AS, Sachdev V, Mahajan N. Comparison of endoflas and zinc oxide eugenol as root canal filling materials in primary dentition. J Indian Soc Pedod Prev Dent 2014; 32(4):317-21. https://doi.org/10.4103/0970-4388.140958

[18] Damian MF, Cé PS, Luthi LF, Flores ME, Haiter-Neto F. Visual evaluation as a quality control program in Dental Radiology. Rev Odonto Ciênc 2008; 23(3):268-72.

[19] Haffner C, Folwaczny M, Galler K, Hickel R. Accuracy of electronic apex locators in comparison to actual length: an in vivo study. J Dent 2005; 33(8):619-25. https://doi.org/10.1016/j.jdent.2004.11.017

[20] Pilownic KJ, Gomes APN, Wang ZJ, Almeida LHS, Romano AR, Shen Y, et al. Physicochemical and biological evaluation of endodontic filling materials for primary teeth. Braz Dent J 2017; 28(5):578-86. https://doi.org/10.1590/0103-6440201701573. 